\title{
Polymyositis associated with Hodgkin's disease
}

\author{
S. Ng TANG FuI \\ M.Sc., M.B. B.S., M.R.C.P.
}

\author{
R. TEOH \\ M.B. B.S., M.R.C.P.
}

\author{
J. C. Houston \\ M.D., F.R.C.P. \\ Guy's Hospital, London SE1 9RT
}

\begin{abstract}
Summary
A patient is reported who presented with severe polymyositis and pulmonary collapse with infection. Investigations failed to confirm an underlying bronchial carcinoma but post-mortem examination revealed unsuspected Hodgkin's disease. The authors wish to draw attention to the rare but important association between polymyositis and treatable lymphomas.
\end{abstract}

\section{Introduction}

Polymyositis occurring in patients over the age of 40 years is associated with a high incidence of malignancy (Pearson and Currie, 1974). The tumour is most frequently a carcinoma arising from the bronchus, prostate, breast, ovary, uterus or gastrointestinal tract but may remain undiagnosed in spite of extensive investigations (Pearson and Currie, 1974). The authors wish to report a patient with polymyositis who was found to have unsuspected Hodgkin's lymphoma at post-mortem. This association although rare has important diagnostic and therapeutic implications in the management of patients who present with polymyositis.

\section{Case report}

A 57-year-old man was admitted complaining of a productive cough and increasing breathlessness for a few days. Over the previous 3 months he had noticed progressive wasting and weakness of the proximal limb muscles and exertional dyspnoea. He smoked 20 cigarettes per day but had no other relevant history. On examination he was pyrexial $\left(38^{\circ} \mathrm{C}\right)$ with signs of left pulmonary consolidation, marked proximal wasting and weakness of the arms and legs as well as wasting of the accessory muscles of respiration. There was no skin rash, finger clubbing, lymphadenopathy or hepatosplenomegaly. A clinical diagnosis of pneumonia and polymyositis was made and an underlying bronchial carcinoma was suspected
Chest X-ray showed left lower lobe collapse with consolidation and a raised left diaphragm. Elevated serum creatinine kinase of 329 u./1 (normal range $<90$ u./l), electromyography and needle muscle biop\$y of the quadriceps confirmed active myositis. Liver function tests were normal. Haemophilus sp. wass grown from sputum but no malignant cells we seen. After initial treatment with antibiotics fibleoptic bronchoscopy performed on 2 occasions showed narrowing of the left lower lobe bronchus but no malignancy was found on biopsy of the bronchial mucosa. Prednisolone $60 \mathrm{mg}$ daily फ़ें̈ duced little improvement in the muscle weakness:arid after several weeks the dose was reduced to $30 \mathrm{nmg}$ daily because of severe steroid side effects. A repeeat needle muscle biopsy showed persistent myositis. Azathioprine $150 \mathrm{mg}$ daily was added but the muscle weakness and dyspnoea continued to get worse aid he died 5 months after presentation following further episode of pneumonia.

At post-mortem, besides extensive bronchipneumonia, the left lower lobe bronchus was fourd to be compressed and invaded by an enlarged noge infiltrated by Hodgkin's lymphoma of mixed cellula ity. The para-aortic and coeliac nodes which were slightly enlarged, and a small splenic nodule showed similar histological changes. Both diaphragms, intercostal and limb muscles were wasted and showed extensive fibrosis, lymphocytic infiltration and necrosis with regeneration of the muscle fibres:

\section{Discussion}

Middle-aged and elderly patients with poly myositis often have an underlying malignancy which may be overt or occult. Their poor prognosis $\stackrel{a}{t}$ usually due to the relentless progression of musale weakness in spite of steroid treatment, rather than to the direct effects of the tumour (Pearson and Currie, 1974). However, in some cases the polymyositis may improve if the neoplasm is diagnosed and treated 
successfully (Pearson and Currie, 1974). Consequently a careful clinical examination including rectal and pelvic examination, chest and gastrointestinal tract $\mathrm{X}$-rays should be performed to exclude the commonly associated carcinomas.

The association of polymyositis and Hodgkin's lymphoma has only rarely been described (Arundell, Wilkinson and Haserick, 1960; Currie et al., 1970). Arundell et al. (1960) reported on a 46-year-old woman with dermatomyositis which was followed 30 months later by the development of Hodgkin's disease. The dermatomyositis flared up with each exacerbation of the lymphoma and responded when the malignancy was treated. Their patient was still alive 5 months after the diagnosis and treatment of the Hodgkin's disease.

In the present case, death resulted from progressive muscle weakness and complicating respiratory infection but the prognosis might have been favourably altered if the underlying lymphoma had been diagnosed and successfully treated. In view of the good response of Hodgkin's disease to modern treatment the authors wish to emphasize that an associated lymphoma, although rare, should always be considered in patients who present with polymyositis.

\section{Acknowledgments}

We thank Dr R. A. C. Hughes and Dr J. Abdulla of Guy's Hospital in connection with this case report.

\section{References}

ARUNDEll, F.D., Wilkinson, R.E. \& Haserick, J.R. (1960) Dermatomyositis and malignant neoplasm in adults. A survey of twenty years' experience. Archives of Dermatology, $82,722$.

Currie, S., Henson, R.A., Morgan, H.G. \& Poole, A.J. (1970) The incidence of the non-metastatic neurological syndrome of obscure origin in the reticulosis. Brain, 93, 629.

Pearson, C.M. \& Currie, S. (1974) Polymyositis and related disorders. In: Disorders of Voluntary Muscle (Ed by Walton, J.N.), 3rd edn, pp. 624-625. Churchill Livingstone, Edinburgh. 